\title{
ORIGINAL PAPERS
}

Dent. Med. Probl. 2016, 53, 1, 111-117

DOI: $10.17219 / \mathrm{dmp} / 60840$ (c) Copyright by Wroclaw Medical University and Polish Dental Society ISSN 1644-387X

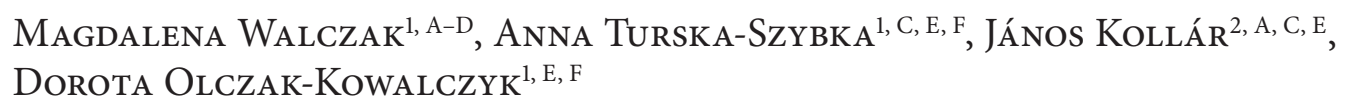

\section{Music in the Dental Office \\ - Preferences of Budapest Inhabitants}

\section{Muzyka w gabinecie stomatologicznym \\ - preferencje mieszkańców Budapesztu}

${ }^{1}$ Department of Pediatric Dentistry, Medical University of Warsaw, Warsaw, Poland

${ }^{2}$ Institute of Behavioral Sciences, Semmelweis University, Budapest, Hungary

A - research concept and design; $\mathbf{B}$ - collection and/or assembly of data; $\mathbf{C}$ - data analysis and interpretation;

$\mathbf{D}$ - writing the article; $\mathbf{E}$ - critical revision of the article; $\mathbf{F}$ - final approval of article

\begin{abstract}
Background. It is believed that listening to music can have a positive influence on stress reduction prior to medical procedures.

Objectives. The purpose of this study was to assess music preferences among dental patients in Budapest.

Material and Methods. The research involved examination of 104 patients with the use of an anonymous survey which consisted of 8 questions concerning: age, sex, subjective evaluation of anxiety prior to dental treatment and overall evaluation of music significance. Afterward, the participants were asked to select a type of music they are most likely to listen to during dental treatment and to specify if they would choose headphones or not. The questionnaire was drawn up in two language versions: Hungarian and English.

Results. The choices made by women and men were not significantly different. Women chose classical music $(43.33 \%)$, pop music $(25 \%)$ and the sounds of nature $(18.33 \%)$ as the most likely to listen to while being treated by a dentist. Men's answers were more differentiated: $25 \%$ of male responders indicated classical music and rock music, pop music $-20.45 \%$, the newest hits $-18.18 \%$, hip hop and soundtracks $-15.91 \%$ respectively. A comparable number of men and women would prefer silence during the dental appointment. The majority of the respondents, regardless of their gender, declared they would prefer to listen to music from the speakers.

Conclusions. The appropriate selection of music and the way of listening to it may significantly contribute to a patient-friendly atmosphere at the dentist's office. Patients whose anxiety is reduced by the application of audio analgesia may return to a given office more eagerly and their treatment might be more effective (Dent. Med. Probl. 2016, 53, 1, 111-117).
\end{abstract}

Key words: dental anxiety, dental treatment, music therapy, audioanalgesia.

Słowa kluczowe: lęk w stomatologii, leczenie stomatologiczne, leczenie muzyką, audioanalgezja.

Most people associate their visit to the dentist's office with feelings of anxiety and discomfort. The lack of knowledge about the treatment and waiting intensify their fear which may turn into dentophobia, and even make the patients avoid the visits to the dentist's office [1].

There are plenty of studies devoted to the influence of music on stress reduction prior to medical procedures [2-7]. Researchers usually conduct general examinations regarding this issue, with- out narrowing the subject of their research to one specific type of music. It is possible that the study from 1929, in which Vincent and Thompson presented their thesis that the fact of listening to music is more crucial for the therapy than the type of music itself, resulted in limited research on various types of music used in audio analgesia [2].

Burns [8] reported that different types of music have a different effect on stress. Generally in his study it was hypothesized that listening 
to classical music is relaxing whereas listening to hard rock music increases the level of physiological arousal. Even though the study admittedly did not prove that classical music decreases anxiety, it was revealed that individuals who listened to hard rock music during the examination were less resistant to stress and their ability to relax was compromised. What is worth mentioning, according to Burns, is that in those individuals who were not exposed to any music, the level of relaxation was higher. The concept that music can be an efficient tool in modifying patients' mood and psychological responses was an origin to further findings that the slower the music is the lower physiological arousal gets and vice versa [8].

A comprehensive and detailed meta-analysis by Stanley on music in medicine refers to dental treatment and its correlation with music and specific psychological processes [2]. In addition, the fact that music has a considerable effect on coping with stress and promoting relaxation has already been proven in numerous studies $[3,4,8,9]$.

The analgetic effect of music may be achieved by means of auditory factors in several ways, such as: direct suppression of neurological pain, masking the sound of the dental drill, distracting from the dental procedure, providing the impression of being more in control due to the possibility of controlling the volume and type of music [9].

The purpose of the research was to gain answers to the following questions:

- 1: Does gender have an influence on the choice of music in a dental office?

- 2: What is the most popular kind of music among the questioned people?

- 3: What is the least popular kind of music among the questioned people?

- 4: What kind of device would be chosen: headphones or loudspeakers?

\section{Materials and Methods}

The questionnaire was addressed to a group of men and women living in Budapest and conducted from March until May 2013. The majority of them were Hungarians, but some foreigners were also surveyed. 104 potential patients (60 women and 44 men) participated in the research. The patients were divided into four groups: less than 18 years of age, 19-35 years old, 36-65 years old and over 66 years of age. The intention was to categorize the participants according to their professional activity: minors, working population and people who have reached pension age. The anonymous survey consisted of 8 questions concerning age, sex, subjective evaluation of anxiety prior to dental treatment and overall evaluation of music significance. Afterwards, the participants were asked to select a type of music they are most likely to listen to during dental treatment. Each person could mark as many kinds of music as they wanted, choosing from the following options: classical music, pop music, the newest hits, rock, techno, hip hop, heavy metal, the sounds of nature and soundtracks. The patients could also write down their own suggestions of the kind of music they prefer. Those not willing to listen to any type of music during a dental appointment could mark that they prefer silence. At the end, the participants were asked to specify if they tend to choose headphones or speakers.

Data analysis was performed using Statgraphics statistical program. The results were statistically analyzed using the chi-square test with the level of significance set at 0.05 .

\section{Results}

The total number of male and female participants is illustrated in Figure 1. According to the survey, music plays an important role in the life of the Budapest inhabitants, which is illustrated by Figure 2. According to Figure 3, the majority of respondents are accompanied by music during their daily life activities. The next aim of the questionnaire was to assess when the dental patients feel the strongest fear before the dental appointment. Generally speaking, $81.67 \%$ of women and $63.64 \%$ of men declared feeling anxiety prior to the dental treatment (Figure 4).

The primary purpose of the questionnaire was to assess what kind of music would be the most popular among the questioned people. The profile of the answers given by male and female respondents is illustrated in Figure 5. The next goal of our survey was to compare the way of listening to music according to the gender. The respondents were asked if they prefer listening to the music through the speakers or by means of headphones. The responses of women and men were as shown in Figure 6.

\section{Discussion}

According to the research, significant relationships between gender and music preferences were found in the case of classical music, sounds of nature, rock music and hip hop. Although, there are some similarities which refer to several of the suggested types of music, the majority of results was different. Thus, gender has an influence on the choice of music in a dental office. 
* statistically significant difference between men and women $(p<0.05)$

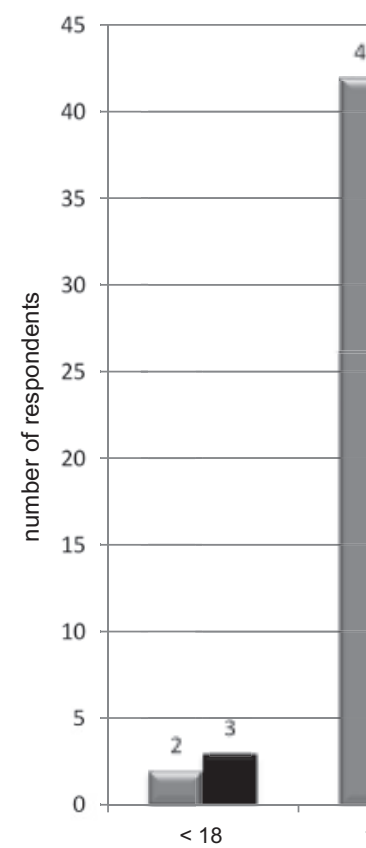

42

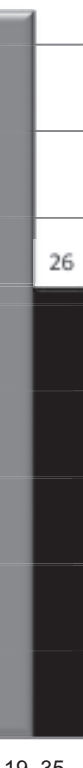

19-35

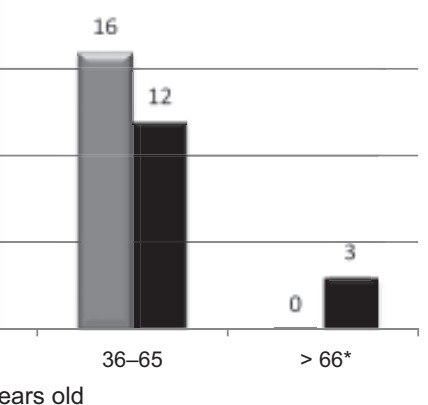

years old

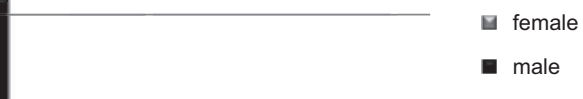

a male
Fig. 1. Patient's age
Fig. 2. Does music help you relax?
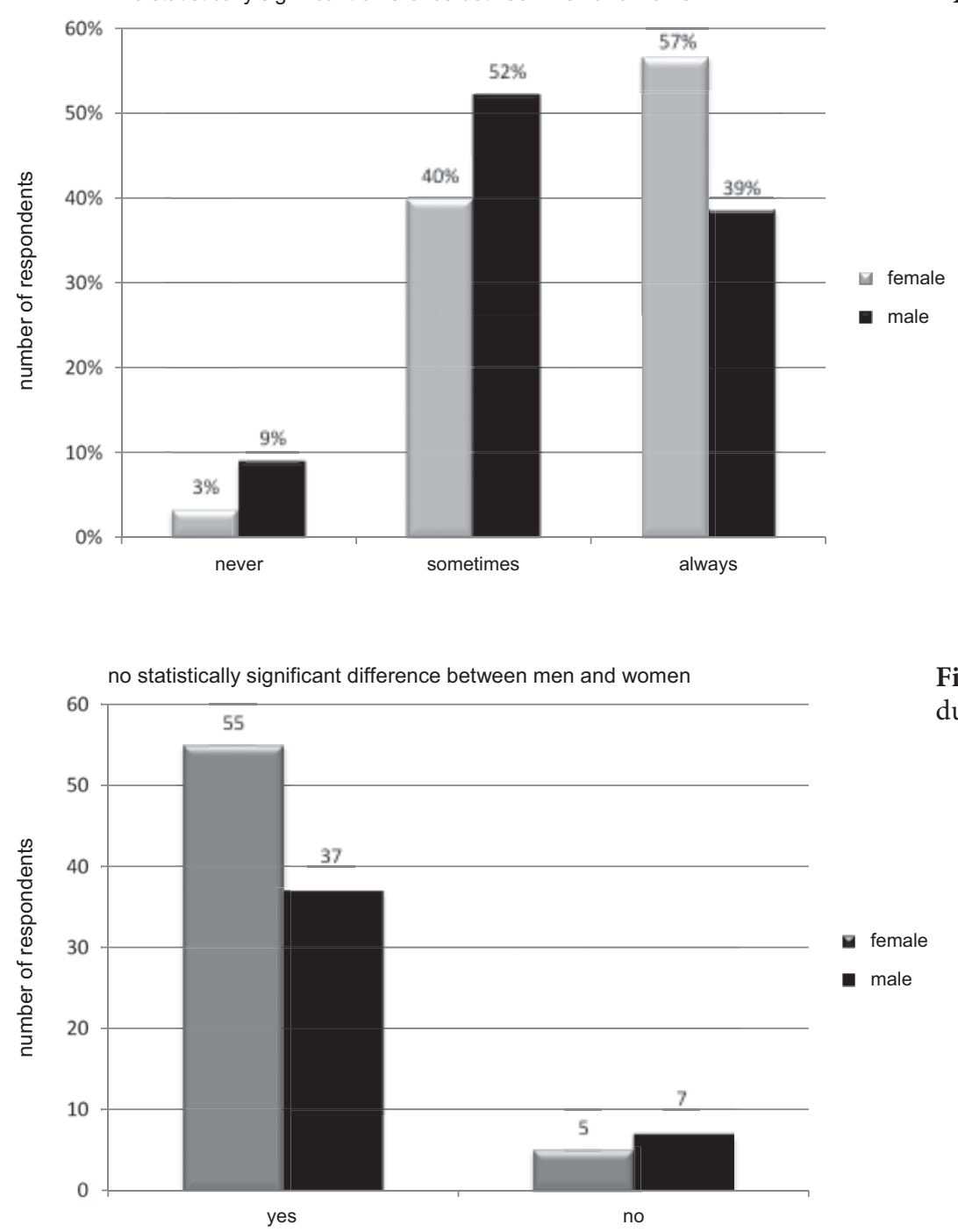

Fig. 3. Does music accompany you during your daily life activities? 


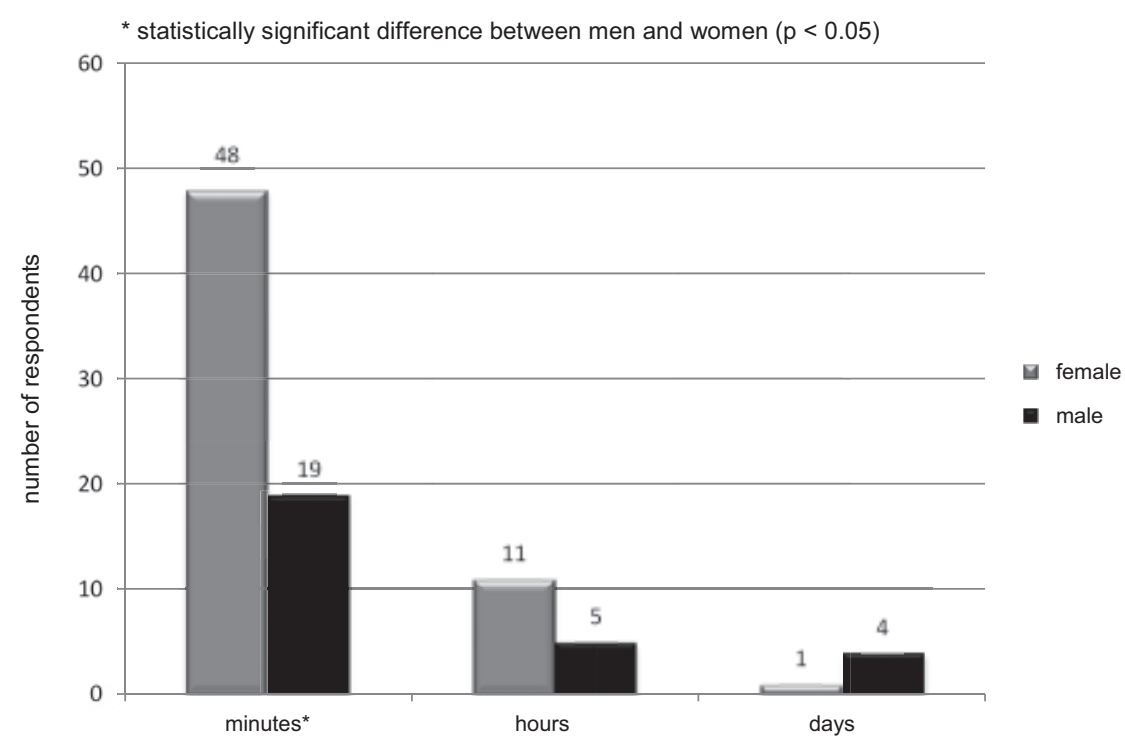

Fig. 4. When do you feel the strongest fear prior to dental treatment?

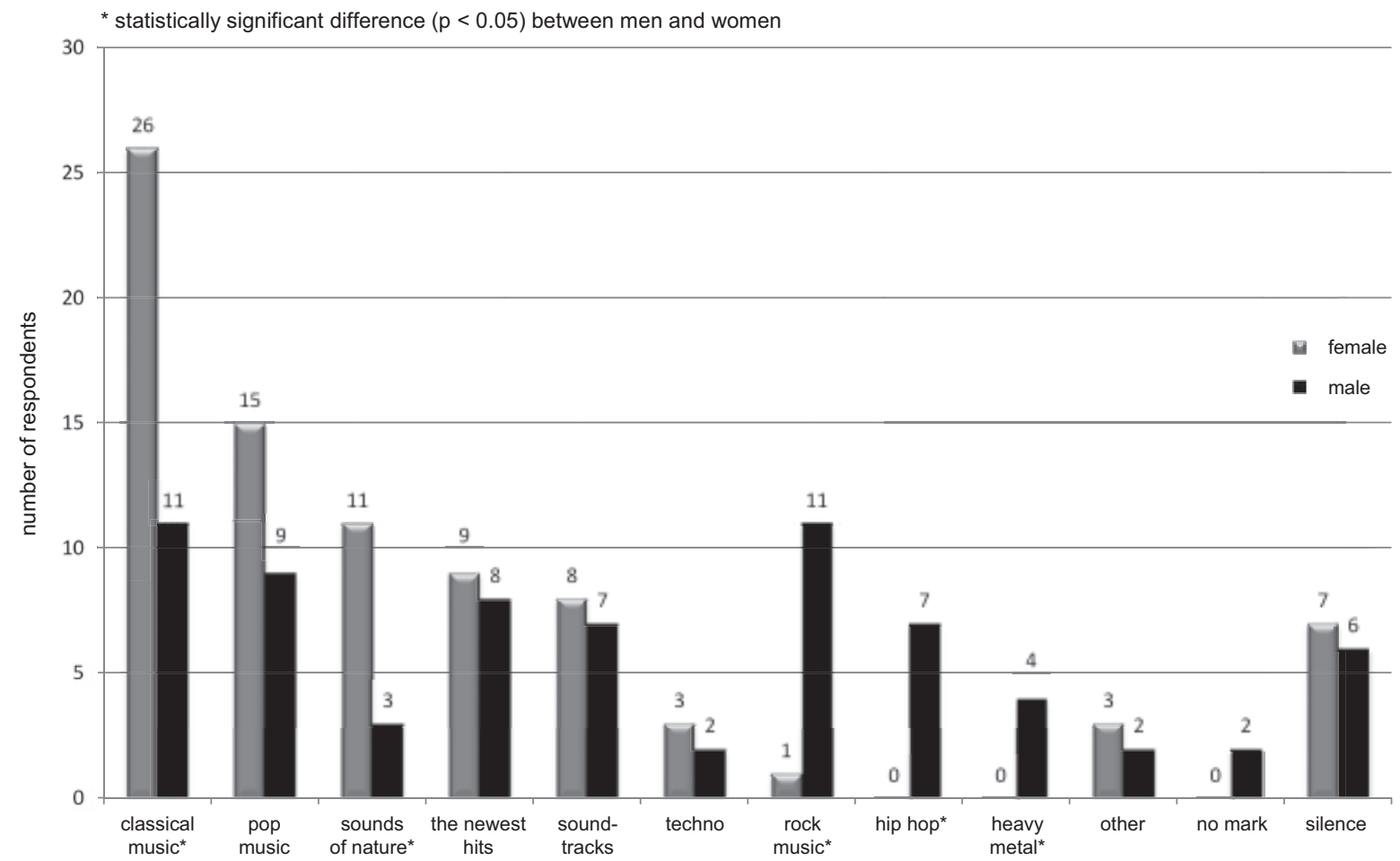

Fig. 5. What kind of music would you prefer during a dental appointment?

The findings of the current study show that classical music was most often chosen by women. Previous studies confirm that classical music may be found as a way to calm down and get rid of fear and anxiety [10]. However, this kind of music might be regarded as ambiguous. One can find it difficult to adjust a suitable piece of classical music to alleviate patients' apprehensions as classical music does not always correspond to the inner feeling state [10].

According to this study, the second most popular choice among female respondents was popular music. As opposed to classical music, popular music is literal due to the lyrics, which can stimulate patients' thoughts. Thus, by means of pop mu- sic with a positive message, dentists can induce relaxation and appeasement in the patient [10].

The choices made by men were more differentiated than those of women but classical music and rock music were found equally popular among male respondents. The findings of the previous articles show that rock music has been a matter of controversy for the few past years and it has both its followers and opponents [11-15]. The fact that so many male respondents chose rock music as their favorite type of music may be based on the statement that it might cause euphoria and excitement, and thus can help to relax and divert attention from stress during treatment [16]. 


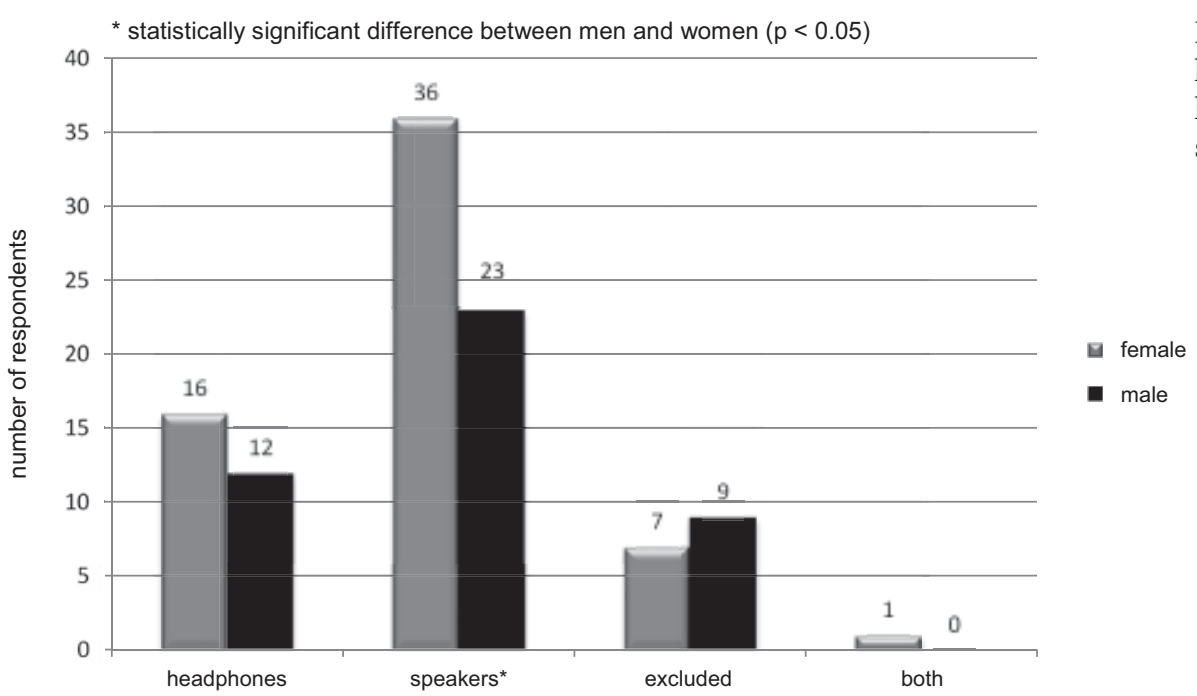

Fig. 6. Would you like to listen to music by means of headphones or through the speakers?
Taking the results into account, none of the female respondents marked hip hop and heavy metal. It is still unclear why people find heavy metal attractive in a certain period of their lives although many researches have tried to find an answer. A strong relation has been observed between reckless behavior and preference for heavy metal [17]. Moreover, heavy metal is likely to be listened to by depressed women with a tendency to selfharm and suicidal thoughts, lower educated people, overusing alcohol and with difficulties at school $[18,19]$. Perhaps the reason why so few people want to listen to heavy metal during their dental appointment lies in the fact that this kind of music is generally considered to have a strong correlation with death, destruction and hopelessness. What is more, it can cause feelings of isolation. A patient who needs to calm down may find it difficult due to the electronic distortion, pounding beat and unclear lyrics, which may cause confusion rather than relaxation [20]. Wooten's research proved that heavy metal is especially popular among teenagers with chemical dependency. Overidentification with violent and rebellious lyrics is still a matter of concern [20].

Hip hop turned out to be the second least popular type of music among women and none of them wanted to listen to it during a dental appointment. This may result from the fact that hip hop is popular mostly among teenagers but this age group was not represented in our study. Additionally, hip hop artists usually use specific language, neologisms and unclear vocabulary. Thus a nonadept listener may find it difficult to understand the message. Moreover, the singers' voices are often emotionally charged and it can affect patients' mood [21].

Regarding the results, techno was found the least popular kind of music among male patients. This may be reflected by the findings from the other authors who showed that the attractiveness of broadly defined electronic music is greater among youth adults using heavy drugs [22]. Additionally, it has been proven that these people have a tendency to suffer from depression, mood irregularities and oral cavity disorders [23]. Listening to fast music, like techno, induces changes in the nervous system, increasing heart rate and systolic blood pressure [19]. Moreover, in the examined subjects, a significant increase in $\mathrm{GH}$, beta-E and ACTH was observed [19].

According to the research, citizens of Budapest prefer listening to music from the speakers over using headphones. $56.73 \%$ of both male and female subjects answered that if they had a choice they would choose speakers. Only $26.92 \%$ of the questioned potential patients would decide to listen to the music through headphones. This situation may be explained due to the fact that headphones might create a feeling of isolation. Moreover, the patients might be scared of the situation that they will not be able to hear the dentist's instructions and follow them. For those patients who are not concerned about the procedure in the dental office, headphones seem to be a good solution. However, dentists should be equipped with a volume controller to make sure that the patient will be able to hear a request or instructions. The next explanation of this outcome might be the fact that headphones are still not very popular in dental offices and a lot of patients probably never had an opportunity to listen to music this way, unless they bring they own music player with headphones. We hypothesize that this ratio will change in the next few years, because more and more people listen to music through headphones on their way to school, work or even at home, just to experience better sound quality.

Music, together with other non-invasive methods, may decrease the level of anxiety and distract 
patients' attention from a dental procedure. Commonly used tranquilizers have a very good relaxing effect or they can even result in a retrograde amnesia. However, in cases of overdosage or misuse, the following side effects can occur: respiratory failure, significant decrease of blood pressure and high temperature. Thus, the application of the proper selection of music seems to be an efficient and safe tool to aid relaxation in patients [24]. Good communication with a patient, abundant empathy and a relevant psychological approach are those priceless approaches which will be appreciated by the patient [25]. Nowadays, many dentists wonder how to make their dental offices more patient-friendly and attractive. With current levels of competition, attracting new patients and keeping the current ones is an important part of dental marketing. Dentists and owners of dental practices, eager to ensure the best conditions and comfort for patients, should bear in mind that the use of music may significantly decrease the level of anxiety in patients [1,2]. A suitable selection of music in the treatment room and in the waiting room is a benefit that more and more patients and their accompanying persons notice. It is worth considering the preferences of the patients and offer them their favorite type of music, both in the waiting room and during a dental procedure. Among the questioned inhabitants of Budapest, classical music, pop music and rock music have the greatest influence on relaxation, whereas heavy metal, hip hop and techno were found the least likely to be chosen. Taking into account the suggested playlist on the questionnaire used in this study, dentists can significantly affect comfort and a sense of security in their patients as well as create more individualized conditions during dental treatment.

Acknowledgment. We would like to show our gratitude to Dariusz Gozdowski, PhD, from the Department of Experimental Design and Bioinformatics, Warsaw University of Life Sciences, for his assistance with the statistics.

\section{References}

[1] Bodner E., IAncu I.: Recalling the threat: Dental anxiety in patients waiting for dental surgery. Isr. J. Psychiatry Relat. Sci. 2013, 1, 61-67.

[2] Standley M.J.: Music research in medical/dental treatment - meta-analysis and clinical applications. J. Music Ther. 1986, 23, 56-122.

[3] Miluk-Kolasa B., Matejek M.: The effect of music listening on changes in selected psychological parameters in adult pre-surgical patients. J. Music Ther. 1996, 33, 208-218.

[4] Lai H.L., Hwang M.J., Chen C.J., Chang K.F., Peng T.C., Chang F.M.: Music may reduce anxiety during invasive procedures in adolescents and adults. J. Clin. Nurs. 2008, 17, 2654-2660.

[5] Zengin S., Kabul S., Al B., Sarcan E., DoĞan M., Yildirim C.: Effects of music therapy on pain and anxiety in patients undergoing port catheter placement procedure. Complement Ther. Med. 2013, 21, 689-696.

[6] Chen L.C., Wang T.F., Shin Y.N., Wu L.J.: Fifteen-minute music intervention reduces pre-radiotherapy anxiety in oncology patients. Eur. J. Oncol Nurs. 2013, 17, 436-441.

[7] Bradt J., Dileo C., Potvin N.: Music for stress and anxiety reduction in coronary heart disease patients. Cochrane Database Syst. Rev. 2013, 12.

[8] Burns J.L.: The effect of different types of music on perceived and psychological measures of stress. J. Music Ther. 2002, 39, 101-116.

[9] Marwah N., Prabhakar A.R., Raju O.S.: Music distraction - its efficacy in management of anxious pediatric dental patients. J. Indian Soc. Pedod. Prev. Dent. 2005, 23, 168-170.

[10] Summer L.: Considering classical music for use in psychiatric music therapy. Music Ther. Perspect. 1994, 12, 130-133.

[11] Petrescu N.: Loud music listening. Mcgill J. Med. 2008, 11, 169-176.

[12] Ter Bogt T.F., Keijsers L., Meeus W.H.: Early adolescent music preferences and minor delinquency. Pediatrics, 2013, 131, 380-389.

[13] Samelli A.G., Matas C.G., Carvallo R.M., Gomes R.F., De Beija C.S., Magliaro F.C., Rabelo C.M.: Audiological and electrophysiological assessment of professional pop/rock musicians. Noise Health, 2012, 14, 6-12.

[14] Vogel I., van de Looij-Jansen P.M., Mieloo C.L., Burdorf A., De WaArt F.: Risky music listening, permanent tinnitus and depression, anxiety, thoughts about suicide and adverse general health. PLoS ONE 2014, 9, 6.

[15] Graham M., Michael C., Colby P.: Adolescent suicide: music preference as an indicator of vulnerability. J. Am. Acad. Child Adolesc. Psych. 1993, 32, 530-535.

[16] Bushong D.J.: Good music/bad music: extant literature on popular music media and antisocial behavior. Music Ther. Perspect. 2002, 20, 69-79.

[17] ARnett J.: Heavy metal music and reckless behavior among adolescents. J. Youth Adolesc. 1991, 20, 573-592.

[18] Martin G., Clarke M., Pearce C.: Adolescent suicide: Music preference as an indicator of vulnerability. J. Am. Acad. Child Adolesc. Psych. 1993, 32, 530-535.

[19] Gerra G., Zaimovic A., Franchini D., Palladino M., Giucastro G., Reali N., Maestri D., Caccavari R., Delsignore R., BRAmbilla F.: Neuroendocrine responses of healthy volunteers to 'techno-music': relationships with personality traits and emotional state. Int. J. Psychophysiol. 1998, 28, 99-111. 
[20] Wooten M.A.: The effect of heavy metal music on affect shifts of adolescent in an impatient psychiatric setting. Music Ther. Perspect. 1992, 10, 93-98.

[21] Chesley P.: You know what it is: Learning words through listening to hip-hop. PLoS ONE 2011, 6, 1-9.

[22] Chinet L., Stéphan P., Zobel F., Halfon O.: Party drug use in techno nights: A field survey among Frenchspeaking Swiss attendees. Pharmacol. Biochem. Biul. 2007, 86, 284-289.

[23] Mulder J., Ter Bogt T.F., Raaijmakers Q.A., Nic Gabhainn S., Monshouwer K., Vollebergh W.A.: Is it the music? Peer substance use as a mediator of the link between music preferences and adolescent substance use. J. Adolesc. 2010, 33, 387-394.

[24] Bae I., Lim H.M., Hur M.H., Lee M.: Intra-operative music listening for anxiety, the BIS index and the vital signs of patients undergoing regional anesthesia. Complement Ther. Med. 2014, 22, 251-257.

[25] Frąckowiak-Świtkowska M.: Positive communication with the patient. Twój Prz. Stomatol. 2013, 7-8, 99-103 [in Polish].

\section{Address for correspondence:}

Anna Turska-Szybka

ul. Miodowa 18

00-246 Warsaw

E-mail: aturskaszybka@orange.pl

Conflict of Interest: None declared

Received: 29.10 .2015

Revised: 20.11.2015

Accepted: 1.12.2015 